\section{Sitios anatómicos para la inserción de microtornillos interradiculares como dispositivos de anclaje temporal en tratamientos de ortodoncia}

\section{Anatomical sites for the insertion of interradicular miniscrews as temporary anchoring devices in orthodontic treatments}

\section{Resumen}

Los microtornillos interradiculares (MTI) son dispositivos de uso temporal diseñados para ser insertados en el hueso alveolar con la finalidad de mejorar el anclaje. El objetivo de este estudio fue presentar una guía para odontólogos que permita identificar los sitios anatómicos más apropiados para la inserción de estos dispositivos, logrando así, una mayor tasa de éxito clínico en los tratamientos. PUBMED, Google Académico y SciELO fueron las bases de datos utilizadas para la búsqueda de la literatura, se consideraron artículos publicados entre los años 2000 y 2020, en inglés y en español. Nuestra revisión sugiere según la bibliografía actual, realizar una planificación al comienzo del tratamiento de ortodoncia, utilizando guías generales para la inserción de MTI a través de mapas visuales de "zonas seguras" que existen entre los espacios interradiculares. Para estos, se consideró que la mínima cantidad de hueso alveolar debía ser de $3 \mathrm{~mm}$.

Palabras clave: Procedimiento de anclaje ortodóncico; Tornillos para huesos; Tomografía computarizada de haz cónico; Radiografía panorámica (fuente: DeCS BIREME).

\begin{abstract}
Interradicular miniscrews (MTI) are temporary devices designed to be inserted into the alveolar bone in order to improve anchorage. The aim of this study was to present a guide for dentists that allows identifying the most appropriate anatomical sites for the insertion of these devices, thus achieving a higher clinical success rate in treatments. PUBMED, Google Scholar and SciELO were the databases used to search the literature; articles published between 2000 and 2020, in English and Spanish, were considered. Our review suggests, according to the current bibliography, planning at the beginning of orthodontic treatment, using general guidelines for the insertion of MTI through visual maps of "safe areas" that exist between the inter-root spaces. For these, it was considered that the minimum amount of alveolar bone should be $3 \mathrm{~mm}$.
\end{abstract}

Keywords: Orthodontic Anchorage Procedures; Bone Screws; Cone-Beam Computed Tomography; Radiography Panoramic (source: MeSH NLM).
ISSN-L 1560-9111; eISSN: 1609-8617

\section{Artículo de Revisión}

\author{
Macarena Figueroa 1,a, Fadua Zafe ${ }^{1, a}$, Cristine Cortínez 1,a, \\ Susana Chamorro 2,a, Valentina Gallardo 2,a \\ 1 Universidad Mayor, Facultad de Odontología, Santiago, \\ Chile. \\ ${ }^{2}$ Universidad de Chile, Facultad de Odontología, Santiago, \\ Chile. \\ ${ }^{a}$ Cirujano Dentista.
}

\section{Correspondencia:}

Macarena Figueroa: macarena.figueroasalinas@gmail.com Armando Moock 3637 DPTO 701, comuna de Macul,

Santiago de Chile.

Código postal: 7830004

ORCID: 0000-0002-4507-3540

\section{Coautoras:}

Fadua Zafe: fadua.zafe@mayor.cl ORCID: 0000-0002-2874-4461

Cristine Cortínez: ccortinezlira@gmail.com ORCID: 0000-0002-4952-103X

Susana Chamorro: schamorropino@gmail.com ORCID: 0000-0003-2748-4984

Valentina Gallardo: vale.gallardos@icloud.com ORCID: 0000-0002-2322-6235

\section{Editora:}

Sandra Patricia Palomino-Gómez

Universidad Nacional Mayor de San Marcos, Perú.

Conflicto de intereses: los autores declaran no tener conflictos de interés.

Fuente de financiamiento: autofinanciado.

\section{Recibido: $11 / 03 / 20$}

Aceptado: $23 / 07 / 20$

Publicado: $15 / 02 / 21$ 


\section{Introducción}

La preservación del anclaje absoluto en terapias de ortodoncia siempre ha sido un objetivo desafiante, especialmente cuando la planificación de un tratamiento implica la movilización de un grupo de dientes de forma simultánea ${ }^{1,2}$. El anclaje esquelético revolucionó este concepto, proporcionando movimientos dentarios y minimizando los efectos indeseables en la unidad de reacción ${ }^{3}$. Es por esto, que para prevenir efectos secundarios en pacientes donde el anclaje periodontal es pobre, se deben implementar dispositivos adicionales, ya sean, intraorales (ej. botón de nance, microtornillos) o extraorales (ej. arcos extraorales) ${ }^{4-6}$.

Los microtornillos interradiculares (MTI) de ortodoncia son dispositivos intraorales diseñados para insertarse temporalmente en el hueso alveolar interradicular para mejorar el anclaje ${ }^{1}$. Son elementos no oseointegrados, que presentan una superficie pulida con contaminantes propios de fabricación que inhiben la oseointegración ${ }^{7,8}$. Estos han ganado enorme popularidad y aceptación en la comunidad de ortodoncia, debido a su buen rendimiento, simplicidad de inserción/extracción, bajo costo y mínima/nula necesidad de colaboración por parte del paciente ${ }^{8-11}$. Su pequeño tamaño permite que sean insertados en el hueso interradicular expandiendo sus aplicaciones clínicas ${ }^{12}$. Estos se utilizan comúnmente cuando la falta de cooperación del paciente puede causar complicaciones que comprometan los resultados deseados de un tratamiento, cuando la cantidad de dientes no permite un anclaje adecuado y cuando los dientes están comprometidos periodontalmente ${ }^{1,10,13,14}$.

Las siguientes, son indicaciones para el uso de microtornillos en tratamientos de ortodoncia que han sido reportadas en la literatura: verticalización de molares, intrusión del sector anterior, intrusiones individuales, intrusión del sector posterior, mesialización de molares, distalamiento de molares, retracción de frente anterior y distalamiento de caninos, tracciones de piezas incluidas, apoyo de aparatologías, fijación intermaxilar, anclaje en zonas desdentadas, corrección de mordidas abiertas, corrección de líneas medias, corrección de los planos oclusales asimétricos, anclaje para el cierre de espacios de extracciones, extrusión rápida de piezas individuales, expansiones convencionales o asistidas quirúrgicamente, distracciones osteogénicas y en ortodoncia lingual donde la conservación del anclaje es difícil ${ }^{15,16}$.

El objetivo principal de la presente revisión bibliográfica fue presentar una guía para odontólogos que permita identificar los sitios anatómicos más apropiados para la inserción de estos dispositivos, logrando así, una mayor tasa de éxito clínico en los tratamientos.

Se procedió a la búsqueda bibliográfica de artículos en las bases de datos PUBMED, Google Académico y SciELO, que fueron publicados entre los años $2000 \mathrm{y}$ 2020 , en inglés y español. Se evaluaron revisiones bibliográficas, sistemáticas y ensayos clínicos, accediendo a un total de ocho artículos para realizar este manuscrito. Se realizó una estrategia de búsqueda simple y también avanzada utilizando las combinaciones boleanas (AND, OR) de los siguientes términos: procedimiento de anclaje ortodóncico, tornillos para huesos, tomografía computarizada de haz cónico, radiografía panorámica. La selección de los artículos se realizó en un primer tiempo a través de la lectura de abstractos descartando los redundantes y posterior lectura de textos íntegros, seleccionando así los artículos definitivos.

\section{Revisión de la bibliografía actual}

Para realizar estudios diagnósticos y determinar los posibles sitios de inserción de estos MTI sin dañar estructuras anatómicas adyacentes, se han utilizado distintos exámenes imagenológicos complementarios, entre estos destacan las imágenes bidimensionales y tridimensionales.

\section{Imágenes bidimensionales}

Durante décadas las imágenes bidimensionales (2D) se han utilizado para realizar estudios diagnósticos en ortodoncia. Estas incluirán radiografías periapicales, radiografías panorámicas, trazados cefalométricos y fotografías e imágenes de video. Dentro de sus ventajas encontramos su baja o nula dosis de radiación; mientras que dentro de sus desventajas tendremos distorsiones, superposiciones de estructuras y proyecciones por desplazamientos, no entregado información adecuada sobre el espacio interradicular, morfología radicular, grosor del hueso cortical y posición del nervio alveolar inferior ${ }^{9,17,18}$.

\section{Imágenes tridimensionales}

Dentro de las imágenes tridimensionales (3D) más utilizadas tenemos la tomografía computarizada de haz cónico (CBCT), esta permite la evaluación y el análisis de la verdadera anatomía, que hasta hace poco tiempo se limitaban a modelos yeso, o más recientemente, a modelos digitales. En la última década la $\mathrm{CBCT}$ se ha convertido en una fuente importante de datos volumétricos $3 \mathrm{D}$, siendo una herramienta diagnóstica importante. Su dosis de radiación es alta, por lo que se debe considerar reducir al máximo la exposición a esta. Es utilizada en aquellos casos donde la radiografía convencional no puede proporcionar información diagnóstica satisfactoria. Estos casos incluyen a pacientes con paladar hendido, planificación de cirugías ortognáticas, evaluación de dientes incluidos y las posibles reabsorciones radiculares que puedan producir ${ }^{9,17,18}$.

La elección adecuada de los sitios de inserción es crítica; es importante colocarlos donde sea conveniente desde el punto de vista biomecánico y anatómico, sin dañar estructuras circundantes (raíces dentales, seno maxilar, nervio alveolar inferior) ${ }^{1,9}$. Cada zona de inserción tendrá sus ventajas y potenciales limitaciones anatómicas, es por esto, que se debe realizar una ardua investigación de los lugares seguros de inserción y los factores que podrían influir en el fracaso ${ }^{11}$. Estas tasas generales de éxito pueden verse afectadas por distintos factores, algunos relacionados con las características clínicas de los MTI (diámetro y longitud), otros 
factores relacionados con el huésped (lugar de inserción, edad, sexo, higiene) y factores relacionados con el operador (experiencia clínica al realizar este tipo de procedimientos) ${ }^{6,9,11,12,19-23}$. Ejemplos de las posibles complicaciones producidas por la inserción de estos dispositivos, son la perdida de la vitalidad pulpar, osteoesclerosis y anquilosis dental, las cuales ocurren por trauma en el ligamento periodontal o en las raíces que están en relación a estos, lo que conlleva a una disminución en las tasas de éxito clínico ${ }^{24}$.

La aplicación clínica de un MTI no garantiza el éxito de tratamiento, su estabilidad es esencial antes de que pueda usarse para diferentes modalidades de tratamientos ${ }^{9}$. La tasa de éxito oscila entre un 61 a un $100 \%$, tal como se aprecia en la Tabla 1.

Tabla 1. Tasa general de éxito en el uso de microtornillos interradiculares

\begin{tabular}{|c|c|c|}
\hline Autores (et al) & Año & Tasa de éxito (\%) \\
\hline Park H S 12 & 2006 & 91,6 \\
\hline Motoyoshi M²5 & 2006 & 85,5 \\
\hline Kuroda $S^{26}$ & 2007 & 90 \\
\hline Moon $\mathrm{CH}^{27}$ & 2008 & 83,8 \\
\hline Wu T Y22 & 2009 & 89,9 \\
\hline Galimidi V K ${ }^{28}$ & 2010 & 71 \\
\hline $\operatorname{Lim} H J^{21}$ & 2011 & 93,1 \\
\hline Tepedino $\mathrm{M}^{1}$ & 2018 & Entre 61 a 100 \\
\hline
\end{tabular}

Muchos autores han definido mapas de "zonas seguras" para la inserción de MTI, algunos utilizando radiografías panorámicas ${ }^{1,9,14}$, CBCT ${ }^{1,9,14,29,30}$ y otros complementando estos exámenes con modelos de estudios digitales ${ }^{1,14,29}$.

\section{Valoración del uso de la radiografía panorámica para la inserción de microtornillos interradiculares}

Estudios han evaluado mediante la utilización de radiografías panorámicas, los sitios interradiculares más idóneos para la inserción de MTI, Schnelle MA et al. ${ }^{31}$ evaluaron los espacios antes y después de realizar la alineación de las piezas dentarias con ortodoncia, determinaron un aumento en el número de sitios óseos interradiculares adecuados para la inserción de estos dispositivos, estimaron también que las zonas donde había un mayor stock óseo para su colocación era principalmente en las regiones posteriores tanto del maxilar como de la mandíbula, siendo la zona apical a la mitad de la longitud radicular la zona más apropiada (siempre y cuando se encuentren en encía adherida).

Por otro lado, Wey MC et al..$^{32}$ al comparar las radiografías panorámicas con las imágenes obtenida por el CBCT, se percataron que los resultados obtenidos de la evaluación de las películas radiográficas panorámicas subestimaron ligeramente los espacios obtenidos por el CBCT.
Tanto Schnelle MA et al. ${ }^{31}$, como Wey MC et al. ${ }^{32}$, coincidieron que el uso de radiografías panorámicas entregaba una visión limitada, ya que, las distorsiones verticales y horizontales son inherentes de esta técnica, afectando en mayor medida ciertas regiones (línea media y región canino-premolar). Definieron que la presencia de al menos 3 a $4 \mathrm{~mm}$ de espacio entre dos raíces era considerado como un lugar seguro para la inserción de los MTI. Se eligió esta cantidad de espacio, ya que, el diámetro promedio de estos dispositivos varía entre 1,2 y $2 \mathrm{~mm}$, y debe haber al menos $1 \mathrm{~mm}$ de hueso alrededor para evitar daños en las raíces adyacentes durante su inserción ${ }^{1,14,31-33}$.

Landin $\mathrm{M}$ et al. ${ }^{9}$ expusieron que los métodos diagnósticos más comunes utilizados para la inserción de MTI eran las radiografías periapicales y panorámicas. Estos dos exámenes son fáciles de adquirir, pero están limitados a su bidimensionalidad. Su estudio sugiere que, la inserción a ciegas, la radiografía periapical y la radiografía panorámica, no son confiables para la evaluación de posibles sitios de inserción de MTI, estas se deben complementar con imágenes tridimensionales. En su artículo obtuvieron el porcentaje de perforación de raíces adyacentes a los sitios de inserción que presentaban estas tres técnicas, dando un 55\% de pacientes afectados al usar el método a ciegas, un $60 \%$ de los casos cuando se usaron radiografías periapicales y un $50 \%$ cuando se usaron radiografías panorámicas.

\section{Valoración del uso de tomografía computarizada de haz cónico (CBCT) para la inserción de microtornillos interradiculares:}

Otros estudios evaluaron la utilización de CBCT para determinar los sitios interradiculares más idóneos para la inserción de MTI, estos se encuentran resumidos en la Tabla 2 y serán detallados más adelante.

Poggio PM et al. ${ }^{34}$ tenía como objetivo proporcionar un mapa anatómico para ayudar al clínico en la inserción de MTI en un lugar seguro entre las raíces dentales. Para esto se examinaron CBCT, para cada espacio interradicular se midieron las distancias mesio-distal y vestíbulo-lingual a los 2, 5 y $11 \mathrm{~mm}$ de la cresta alveolar. En el maxilar, la mayor cantidad de hueso mesio-distal estaba por palatino entre el segundo premolar/primer molar, la menor cantidad de hueso estaba en la tuberosidad, el mayor grosor del hueso en la dimensión vestíbulo-palatina fue entre el primer/segundo molar, mientras que el menor se encontró en la tuberosidad. En la mandíbula, la mayor cantidad en dimensión mesio-distal fue entre el primer/segundo premolar, la menor cantidad de hueso estaba entre el primer premolar/canino, en la dimensión vestíbulo-lingual, el mayor grosor fue entre el primer/segundo molar y la menor cantidad de hueso fue entre el primer premolar/canino.

Por otro lado, Deguchi T et al..$^{30}$ a través de CBCT, tuvieron como propósito evaluar cuantitativamente el grosor del hueso cortical en varios lugares del maxilar y la mandíbula, además de las distancias entre la superficie ósea intercortical/superficie de la raíz y las distancias entre 
Tabla 2. Resumen de la valoración del uso de CBCT para la inserción de microtornillos interradiculares

\begin{tabular}{|c|c|c|c|}
\hline Autor et al. & Año & Zonas maxilares más aptas para la inserción de MTI & Zonas mandibulares más aptas para la inserción de MTI \\
\hline Poggio PM $^{34}$ & 2006 & $\begin{array}{c}\text { Entre segundo premolar/primer molar y primer/segundo } \\
\text { molar. }\end{array}$ & Entre primer/segundo premolar y primer/s \\
\hline Deguchi $\mathrm{T}^{30}$ & 2006 & Mesial o distal del primer molar. & Mesial o \\
\hline Flores $\mathrm{SA}^{10}$ & 2008 & Zonas posteriores y entre canino/incisivo lateral. & Entre premolares. \\
\hline $\mathrm{Kim} \mathrm{SH}^{35}$ & 2010 & Entre segundos premolares/primeros molares. & Entre segundos premolares/primeros molares. \\
\hline Fayed $\mathrm{MM}^{36}$ & 2010 & $\begin{array}{l}\text { Entre incisivo lateral/canino, segundo premolar/primer } \\
\text { molar y primer/segundo molar. }\end{array}$ & $\begin{array}{l}\text { Entre incisivo central/incisivo lateral, segundo premolar/ } \\
\text { primer molar y primer/segundo molar. }\end{array}$ \\
\hline Holmes $\mathrm{PB}^{29}$ & 2015 & Centro del área interradicular. & Centro del área interradicular. \\
\hline Tepedino $\mathrm{M}^{14}$ & 2017 & $\begin{array}{l}\text { Entre primeros molares/segundos premolares, caninos/ } \\
\text { incisivos laterales y entre los dos incisivos centrales. }\end{array}$ & Entre los segundos molares/primeros premolares. \\
\hline Tepedino $\mathrm{M}^{1}$ & 2018 & Entre incisivos centrales. & Entre los segundos molares/primeros premolares. \\
\hline
\end{tabular}

las raíces de los premolares/ molares para determinar la longitud y el diámetro aceptable del MTI. Este estudio muestra que la ubicación más segura para colocarlos era por mesial o distal del primer molar, teniendo estos dispositivos un tamaño de $1,5 \mathrm{~mm}$ de diámetro y aproximadamente 6 a $8 \mathrm{~mm}$ de longitud.

Flores SA et al. ${ }^{10}$ obtuvo como resultado que, en el maxilar, existía mayor cantidad de hueso en dimensión mesio-distal en la zona posterior, la zona palatina presentaba mayor cantidad de hueso que la zona vestibular, se encontró también un adecuado margen de espacio interradicular entre segundos premolares/molares, y entre canino/incisivo lateral; en la mandíbula la mayor cantidad de hueso en sentido mesio-distal se observó entre premolares, la distancia interradicular aumentaba a medida que se alejaban de la cresta alveolar. Por lo que a modo de resumen las zonas más aptas para la inserción de los MTI fueron: maxilar, zonas posteriores y entre canino/incisivo lateral; mandíbula, entre premolares.

Kim SH et al. ${ }^{35}$ realizo un estudio en el que su objetivo fue medir en un grupo de pacientes el espacio interradicular entre segundos premolares/primeros molares maxilares, estos son sitios donde a menudo se colocan este tipo de MTI. Como resultado obtuvo que el espacio interradicular se ensanchaba hacia el área apical. Gracias a esto, determinaron pautas para la inserción segura, estas fueron las siguientes: el punto inicial para la colocación del MTI fue cerca de la línea mucogingival $(2$ a $4 \mathrm{~mm}$ desde la unión amelocementaria), con un MTI de 1,4 a 1,8 mm de diámetro y longitud de aproximadamente $6 \mathrm{~mm}$.

También Fayed MM et al. ${ }^{36}$, utilizando CBCT determinaron los sitios óptimos para la inserción de MTI en base a: mapeos dimensionales de los espacios interradiculares, grosor del hueso cortical, edad y sexo. Se realizaron las siguientes mediciones interradiculares: grosor óseo vestíbulo-lingual, espacios mesio-distales tanto vestibulares como palatinos/linguales, espesores corticales vestibulares y palatinos/linguales. Como resultado obtuvo que, en el maxilar, el grosor vestíbulo-lingual más grande era entre primer/segundo molar, la mayor distancia mesio-distal/ vestíbulo-palatina fue entre segundo premolar/primer molar, el mayor grosor de la cortical vestibular fue entre primer/segundo premolar, el mayor grosor cortical palatino fue entre incisivos centrales/ laterales. En la mandíbula, el grosor cortical vestibular más grande se encontraba entre primer/segundo molar, la distancia vestíbulo/mesio-distal mayor fue entre segundo premolar/primer molar, la mayor distancia lingual/ mesio-distal fue entre primer/segundo premolar, el mayor grosor cortical lingual fue entre canino/primer premolar. Los hombres y el grupo de mayor edad tenían espesores corticales vestíbulo-linguales y vestíbulo-palatinos significativamente más altos en sitios específicos del maxilar y la mandíbula.

Holmes $\mathrm{PB}$ et al..$^{29}$ midieron a través de CBCT el grosor del hueso cortical en un punto mesial, medio y distal en las áreas interradiculares, obteniendo que, el hueso cortical es significativamente más delgado en el centro entre dos dientes que en áreas adyacentes a las raíces, y que, al colocarlos ahí disminuye el riesgo de tener contacto con las raíces o la invasión del ligamento periodontal, disminuyendo así las tasas de falla.

\section{Valoración del uso de la radiografía panorámica y/o la CBCT en conjunto con modelos digitales para la inserción de microtornillos interradiculares}

Tepedino $\mathrm{M}$ et al. ${ }^{14}$ definieron un mapa de espacios interradiculares donde los MTI se podían insertar de acuerdo a la disponibilidad de espacio y apiñamiento dentario. Para esto evaluaron los espacios utilizando radiografías panorámicas en conjunto con modelos digitales, efectuando análisis estadísticos de las posibles influencias que tenía el apiñamiento dentario sobre los espacios interradiculares. Como resultado obtuvieron que, en la mandíbula, los sitios más convenientes para la inserción de MTI estaban comprendidos entre segundos molares/ primeros premolares; en el maxilar, entre primeros molares/ segundos premolares, caninos/ incisivos laterales y entre los dos incisivos centrales. Los espacios interradiculares entre caninos/ incisivos laterales maxilares, y entre primeros/ segundos premolares mandibulares revelaron estar influenciados por la presencia de apińamiento dentario, si este era severo, el espacio 
interradicular real en algunas áreas podía ser significativamente diferente de lo que informa el promedio.

Un año más tarde Tepedino $\mathrm{M}$ et $a l .{ }^{1}$ realizo un nuevo estudio con el fin de definir un nuevo mapa de "zonas seguras", donde comparó los espacios interradiculares medidos en radiografías panorámicas (Figura 1A) con los obtenidos mediante CBCT (Figura 1B). De la misma manera que lo expuesto en su trabajo de investigación realizado un año antes, reveló que algunos espacios disponibles para la inserción de los MTI estaban influenciados por el apiñamiento dentario (Figura 2). Los espacios interradiculares más idóneos para la inserción

$\mathbf{A}$

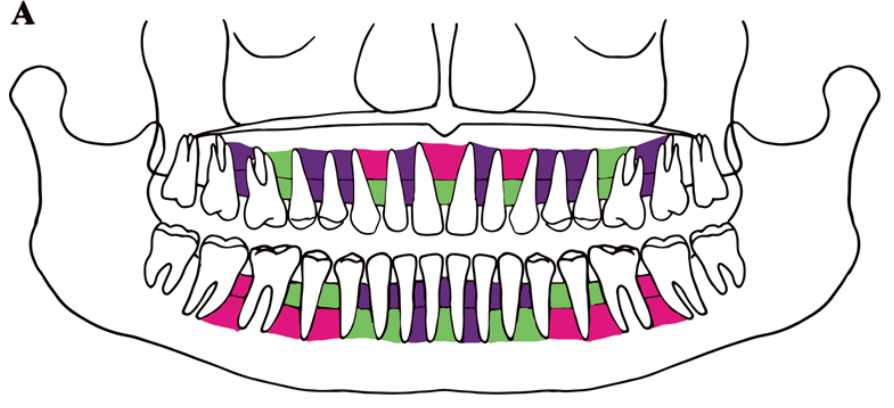

B

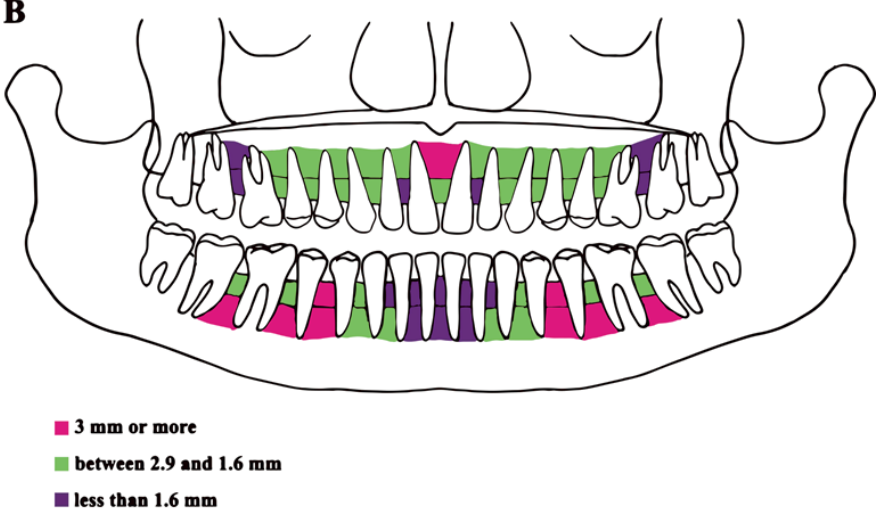

Figura 1. Mapeo de espacios interradiculares. Cada espacio interradicular se divide por una línea en dos partes (que corresponde a las mediciones realizadas en el tercio coronal y en el tercio apical), y se asigna un color a cada una, dependiendo del número de milímetros de espacio encontrado. Rosado= $3 \mathrm{~mm}$ o más; Verde= igual o superior a 1,6 $\mathrm{mm}$; Morado= menos de 1,6 mm. (A) Mapeo de espacios interradiculares en radiografías panorámicas; (B) Mapeo de espacios interradiculares en $\mathrm{CBCT}^{1}$. Figura obtenida y modificada del articulo: https://www.ncbi.nlm.nih.gov/ pmc/articles/PMC6266319/pdf/2176-9451-dpjo-23-05 039e1.pdf
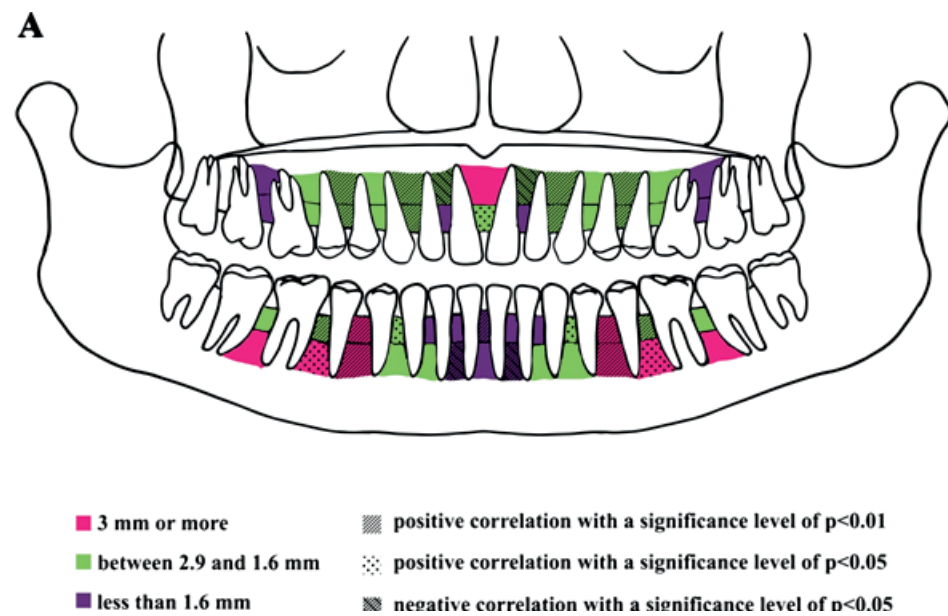

Figura 2. Mapeo de espacios interradiculares medidos en CBCT influenciados por la presencia de apiñamiento. En este caso particular, un coeficiente de correlación positivo, significa que, cuando el apiñamiento aumenta, el espacio interradicular disminuye; mientras que un coeficiente de correlación negativo, significa que, cuando el apiñamiento aumenta, esto resulta en más espacio interradicular, debido a la divergencia de las raíces donde está presente este apiñamiento ${ }^{1}$. Figura obtenida y modificada del articulo: https://www.ncbi.nlm.nih.gov/pmc/articles/PMC6266319/ pdf/2176-9451-dpjo-23-05 039e1.pdf 
de estos dispositivos, en la mandíbula, fueron aquellos situados entre segundo molar/ primer premolar; y en el maxilar entre incisivos centrales.

Con estos resultados, Tepedino $\mathrm{M}$ et al. ${ }^{1}$ recomienda tomar decisiones durante la fase inicial de planificación del tratamiento de ortodoncia, realizando una evaluación preliminar de factibilidad de inserción de un MTI. Esta evaluación puede verse simplificada utilizando el protocolo que se encuentra esquematizado en la Figura 3 ; el cual, debe ser usado en conjunto con la Figura 2.

\section{Conclusión}

Por todo esto, nuestra revisión sugiere realizar una planificación al comienzo del tratamiento de ortodoncia, utilizando guías generales para la inserción de microtornillos interradiculares a través de mapas visuales de "zonas seguras" que existen entre los espacios interradiculares. Para la creación de éstas se consideró el valor mínimo de $3 \mathrm{~mm}$ de hueso disponible entre dos raíces adyacentes para la inserción de un microtornillo interradicular.

\section{Agradecimientos}

A el Dr. Michele Tepedino y a la la Revista Dental Press Journal of Orthodontics - DPJO, que nos concedió el permiso para el uso de las figuras 3,4 y 5 pertenecientes al trabajo titulado "Correlation between tooth size-arch length discrepancy and interradicular distances measured on CBCT and panoramic radiograph: an evaluation

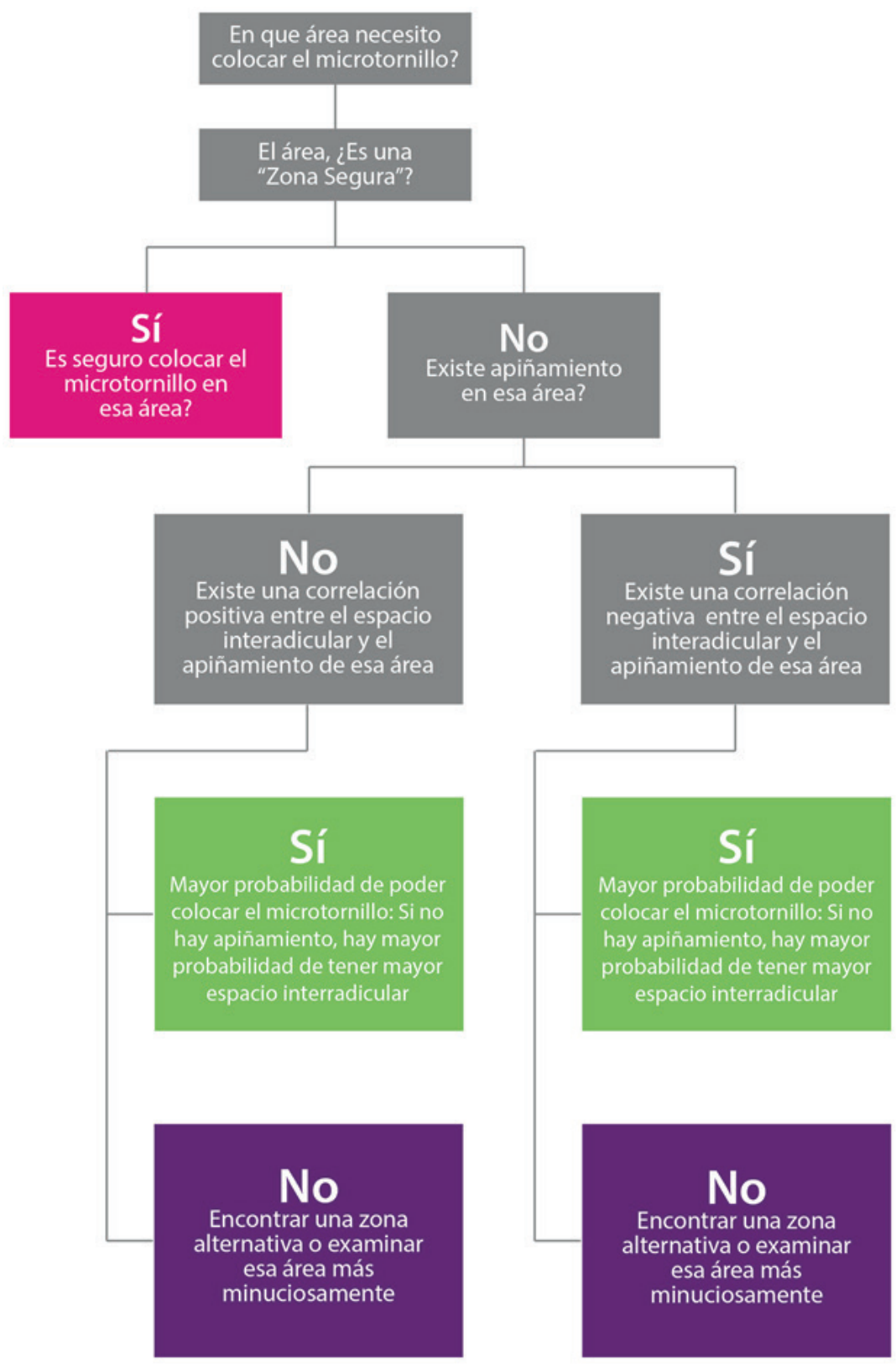

Figura 3. Árbol de decisiones que se utiliza en conjunto con el mapa de la Figura 2, para ayudar a evaluar la posibilidad de inserción de microtornillos interradiculares al comienzo de la planificación de tratamientos de ortodoncia ${ }^{1}$. Figura obtenida y modificada del articulo: https://www.ncbi.nlm. nih.gov/pmc/articles/PMC6266319/pdf/2176-9451-dpjo-23-05 039e1.pdf 
for miniscrew insertion", para hacerlas parte de nuestra revisión bibliográfica.

\section{Referencias bibliográficas}

1. Tepedino M, Cornelis MA, Chimenti C, Cattaneo PM. Correlation between tooth size-arch length discrepancy and interradicular distances measured on CBCT and panoramic radiograph: an evaluation for miniscrew insertion. Dental Press J Orthod 2018;23(5):39.e1-39.e13.

2. Ganzer N, Ganzer N, Feldmann I, Petrén S, Bondemark L. A cost-effectiveness analysis of anchorage reinforcement with miniscrews and molar blocks in adolescents: a randomized controlled trial. Eur J Orthod. 2019;41(2):180-7.

3. Villela H, Laboissière M. Self-tapping Titanium Orthodontic Micro Screw (MPO): New Surgical Protocol and Current Clinical Perspectives. Innov Impl J. 2006;1(1):46-53.

4. Wehrbein H, Göllner P. Skeletal Anchorage in Orthodontics - Basics and Clinical Application. J Orofac Orthop. 2007;68(6):443-61.

5. Pérez-García LM, Garmas CY. Mini implantes, una opción para el anclaje en Ortodoncia. Gac Méd Espirit. 2011;13(3).

6. De La Cruz JO, Villalva JN, Quińones MV, Castagnola FB. Guía radiográfica y quirúrgica para la colocación de microtornillos ortodoncicos. Reporte de caso. Odontol Sanmarquina. 2006;9(2):35-37.

7. Durán F, Hormazábal F, Toledo X, Chang RH, González N, Sciaraffia P. Una Descripción General y Actualizada de Miniplacas y Minitornillos. Efectos Dentoalveolares y Esqueléticos. Int J Odontostomatol. 2020;14(1):136-146.

8. Tepedino M, Cattaneo PM, Masedu F, Chimenti C. Average interradicular sites for miniscrew insertion: should dental crowding be considered? Dental Press J Orthod. 2017;22(5):90-7.

9. Landin M, Jadhav A, Yadav S, Tadinada A. A comparative study between currently used methods and Small Volume-Cone Beam Tomography for surgical placement of mini implants. Angle Orthod. 2015;85(3):446-453.

10. Flores SA, Temoche AH, López AM. Minitornillos: Evidencia anátomotomográfica. Rev Estomatol Hered. 2008;18(2):75-82.

11. Mohammed H, Wafaie K, Rizk MZ, Almuzian M, Sosly R, Bearn DR. Role of anatomical sites and correlated risk factors on the survival of orthodontic miniscrew implants: a systematic review and meta-analysis. Prog Orthod. 2018;19(1):36.

12. Park HS, Jeong SH, Kwon OW. Factors affecting the clinical success of screw implants used as orthodontic anchorage. Am J Orthod and Dentofacial Orthop. 2006;130(1):18-25.

13. Azeem M, Haq AU, Awaisi ZH, Saleem MM, Tahir MW, Liaquat A. Failure rates of miniscrews inserted in the maxillary tuberosity. Dental Press J Orthod. 2019;24(5):46-51.

14. Tepedino M, Masedu F, Chimenti C. Comparative evaluation of insertion torque and mechanical stability for self-tapping and self-drilling orthodontic miniscrews- an in vitro study. Head Face Med. 2017;13(1):10.

15. Chaverri SB, López PC, Valverde MC. Microimplantes, una nueva opción en el tratamiento de Ortodoncia. Odontología Vital. 2016;(25):63-75.

16. Fernández LS, Carralero RC, Castillo ME, Romo UT. Evaluación de microimplantes como unidad de anclaje en movimientos ortodóncicos. 16 de Abril. 2017;56(266):149-156.

17. Kapila S, Conley RS, Harrell WE. The current status of cone beam computed tomography imaging in orthodontics. Dentomaxillofac Radiol. 2011;40(1):24-34.

18. Ludlow JB, Davies-Ludlow LE, White SC. Patient risk related to common dental radiographic examinations: the impact of 2007 International Commission on Radiological Protection recommendations regarding dose calculation. J Am Dent Assoc. 2008;139(9):1237-43.

19. Marquezan M, Souza MM, Araújo MT, Nojima LI, Nojima MC. Is miniscrew primary stability influenced by bone density? Braz Oral Res. 2011;25(5):427-32.

20. Hong SB, Kusnoto B, Kim EJ, BeGole EA, Hwang HS, Lim HJ. Prognostic factors associated with the success rates of posterior orthodontic miniscrew implants: A subgroup meta-analysis. Korean J Orthod. 2016;46(2):111-26.

21. Lim HJ, Choi YJ, Evans CA, Hwang HS. Predictors of initial stability of orthodontic miniscrew implants. Eur J Orthod. 2011;33(5):528-32.

22. Wu TY, Kuang SH, Wu CH. Factors Associated With the Stability of Mini-Implants for Orthodontic Anchorage: A Study of 414 Samples in Taiwan. J Oral Maxillofac Surg. 2009;67(8):1595-9.

23. Gutiérrez LP, Hernández VR, García P, Escudero CN, Bascones MA. Microtornillos: Una revisión. Av Periodon Implantol. 2014;26(1):25-38.

24. Peters FH, Peters FH, Sánchez CZ. Perforación radicular asociada al uso de microtornillos en el anclaje ortodóncico: Reporte de un caso. Rev Clín Periodoncia Implantol Rehabil Oral. 2013;6(3):138-141.

25. Motoyoshi M, Hirabayashi M, Uemura M, Shimizu $\mathrm{N}$. Recommended placement torque when tightening an orthodontic mini-implant. Clin Oral Implants Res. 2006;17(1):109-114.

26. Kuroda S, Sugawara Y, Deguchi T, Kyungy HM, Yamamoto TT. Clinical use of miniscrew implants as orthodontic anchorage: success rates and postoperative discomfort. Am J Orthod Dentofacial Orthop. 2007;131(1):9-15.

27. Moon CH, Lee DG, Lee HS, Im JS, Baek SH. Factors associated with the success rate of orthodontic miniscrews placed in the upper and lower posterior buccal region. Angle Orthod. 2008;78(1):101-106.

28. Galimidi VK. Microtornillos como medio de anclaje en tratamientos de ortodoncia. [tesis de bachiller]. [Santiago]. Facultad de Odontología, Universidad Andrés Bello; 2010.74p. 
29. Holmes PB, Wolf BJ, Zhou J. A CBCT atlas of buccal cortical bone thickness in interradicular spaces. Angle Orthod. 2015;85(6):911-9. DOI: 10.2319/082214-593.1.

30. Deguchi T, Nasu M, Murakami K, Yabuuchi T, Kamioka H, Takano-Yamamoto T. Quantitative evaluation of cortical bone thickness with computed tomographic scanning for orthodontic implants. Am J Orthod Dentofacial Orthop. 2006;129(6):721.e7-721.e12.

31. Schnelle MA, Beck FM, Jaynes RM, Huja SS. A radiographic evaluation of the availability of bone for placement of miniscrews. Angle Orthod. 2004;74(6):832-837.

32. Wey MC, Shim CN, Lee MY, Jamaluddin M, Ngeow WC. The safety zone for mini-implant maxillary anchorage in Mongoloids. Aust Orthod. 2012;28(1):17-21.

33. Choi JH, Yu HS, Lee KJ, Park YC. Three-dimensional evaluation of maxillary anterior alveolar bone for optimal placement of miniscrew implants. Korean J Orthod. 2014;44(2):54-61.
34. Poggio PM, Incorvati C, Velo S, Carano A. "Safe zones": a guide for miniscrew positioning in the maxillary and mandibular arch. Angle Orthod. 2006;76(2):191-197.

35. Kim SH, Kang SM, Choi YS, Kook YA, Chung KR, Huang JC. Cone-beam computed tomography evaluation of mini-implants after placement: Is root proximity a major risk factor for failure? Am J Orthod Dentofacial Orthop. 2010;138(3):264-276.

36. Fayed MMS, Pazera P, Katsaros C. Optimal sites for orthodontic mini-implant placement assessed by cone beam computed tomography. Angle Orthod. 2010;80(5):939-951. 